\title{
Ecological risk assessment of heavy metals in road dust based on improved potential ecological risk index: A case study in Zhengzhou, China
}

\author{
Huina Zhu*, Liangbo Zhang ,Hailiang Zhao, Baozhong Zhang, Hanyu Chen, and fan Shi \\ College of Environmental Engineering, Henan University of Technology, Lianhua Street 100, 450001 Zhengzhou, China
}

\begin{abstract}
In order to analyze the ecological risk of the heavy metals in road dust. The improved potential ecological risk index was established. In the improved method, the toxicity of different chemical speciations of heavy metals were considered. Since residual fraction of $\mathrm{Cd}$ are non-toxic in the improved method, the results of the improved method were much lower than the traditional method.The results showed that the total risks of $3 \#$ and $15 \#$ were medium risk. The highest risk appeared on14\# with the value 337.49 , which belonged to high risk, and the total risk of the other sampling sites were low risk. Therefore, 14\# should be the primary control site. The improved method established in this study is more scientific.
\end{abstract}

\section{Introduction}

With the rapid development of economy and urbanization and the increase of motor vehicle ownership in recent years, air quality has been paid more and more attention. All kinds of solid fuels in production and life are releasing various pollutants into the atmosphere[1]. Road dust is generally formed by atmospheric particles deposition, which can lead to secondary pollution with the driving process of vehicles. At present, many scholars have studied the ecological and health risks of pollutants in air dust or road dust $[2,3]$.

Among various air pollutants, heavy metals are the most harmful pollutants to human health and ecological system[4,5]. Heavy metals in road dust not only affect the growth of plants, but also change the acidity and alkalinity of soil and the supply of nutrients, which has serious effects on the ecological environment $[4,5]$. Therefore, the research on the speciation, distribution characteristics and risk of heavy metals in road dust is one of the hot spots in scientific research.

Many researchers have studied the pollution of trace metals in soil and road dust[6,7]. C. Men studied the sources and risk of heavy metals in road dusts in Beijing[3]. M. Zhang analyzed the sources and health risk assessment of toxic metals in urban soil and road dust in Xining city[5].Zhengzhou is located in Central China, Henan Province, with the dense population and heavy traffic. In winter, the air pollution in heating area is particularly serious. Affected by automobile exhaust, road dust has its own pollution characteristics. At present, there are few reports on the risk analysis of heavy metal in road dust in Zhengzhou. Based on the sampling data of the Third Ring Road in heating season, this study analyzed the pollution and ecological risk of heavy metals in road dust in Zhengzhou City, which can provide certain technical support for the future environmental management.

The main purpose of this study is analyzing the pollution degree and ecological risk of heavy metals in road dust in Zhengzhou. (1) The concentrations of heavy metals, including $\mathrm{Cu}, \mathrm{Zn}, \mathrm{Cd}, \mathrm{Pb}, \mathrm{Mn}, \mathrm{Cr}$, and $\mathrm{As}$ of the road dust in Zhengzhou were monitored; (2)the chemical speciation analysis of heavy metals was carried out; (3) the traditional potential ecological risk of heavy metals was analyzed; (4) the potential ecological risk analysis method based on the chemical forms of heavy metals was established, and the method was applied to the risk of heavy metals in road dust in Zhengzhou.

\section{Materials and methods}

\subsection{Study area}

Zhengzhou, China, the capital of Henan Province, is located in the south of North China Plain. Zhengzhou is located at $112^{\circ} 42^{\prime}-114^{\circ} 13^{\prime}$ east longitude and $34^{\circ}$ $16^{\prime}-34^{\circ} 58^{\prime}$ North latitude. The population density of Zhengzhou ranks the second in the provincial capital cities of China, next only to Guangzhou. Due to the large population and heavy traffic in Zhengzhou, the air pollution caused by human activities and traffic in Zhengzhou is serious. Moreover, since Zhengzhou is located in the plain area. The winter climate is not conducive to air diffusion, and the air pollution in the winter heating season is more serious.

In order to investigate the pollution and the ecological risk of heavy metals in road dust of Zhengzhou.The road dust samples were collected from

* Corresponding author: zhnhnu@163.com 
15 sampling sites in the Third Ring Road of Zhengzhou in winter of 2018.

\subsection{Samples collection}

A total of 15 road samples were collected from Zhengzhou in December 2018. At each sampling site, samples were collected at five sub-sites from $10 \mathrm{~m}^{2}$ road pavement, and each sample size is $>200 \mathrm{~g}$. Then marked the time and place of sampling. The dust was gently swept onto the dustpans using the plastic brushes, and then poured into the self-sealing polyethylene bag. The samples were air-dried in the laboratory and then screened with 200 mesh ( $<75$ channel M) nylon sieve to remove the impurities[8]. Three parallel samples of approximately $0.2000 \mathrm{~g}$ were weighed and waited for digestion.

\subsection{Samples analysis}

Seven typical heavy metals were chosen to be measured in the road dust of Zhengzhou. These were arsenic (As), cadmium (Cd), chromium (Cr), copper $(\mathrm{Cu})$, manganese $(\mathrm{Mn})$, lead $(\mathrm{Pb})$, and zinc $(\mathrm{Zn})$. The total concentrations and fraction of heavy metals in each sample were analyzed. The morphology was extracted by Three-step sequential extraction scheme[9]. After a series of pretreatment, digestion and extraction, the total concentrations and fraction of heavy metals in 15 sampling sites were analyzed by ICP-OES spectrometer.

\subsection{Traditional Potential ecological risk index(IR)}

The risk of heavy metals in the road dust was analyzed by the traditional potential ecological risk index. The formulas are as follows[10]:

$$
\begin{aligned}
C_{f}^{i} & =C_{D}^{i} / C_{R}^{i} \\
E_{r}^{i} & =T_{r}^{i} \times C_{f}^{i} \\
R I & =\sum_{\mathrm{i}=1}^{\mathrm{m}} E_{r}^{i}
\end{aligned}
$$

Where: RI is the total risk; ${ }_{r}^{i}$ refers to the single risk; $T_{r}^{i}$ is the toxicity response $\operatorname{coefficient}(\mathrm{Zn}=1, \mathrm{As}=10$, $\mathrm{Cd}=30, \mathrm{Cr}=2, \mathrm{Hg}=40, \mathrm{Cu}=5, \mathrm{~Pb}=5) ;{ }^{i}$ refers to the pollution factor; $C_{D}^{i}$ is the concentration of heavy metals in the road dust; $C_{f}^{i}$ is the background concentration before industrialization(Background concentration of

\begin{tabular}{|c|c|c|c|}
\hline$E_{r}^{i}$ & $\begin{array}{l}\text { risk level of } \\
\text { single metal }\end{array}$ & RI & $\begin{array}{c}\text { Total risk } \\
\text { level }\end{array}$ \\
\hline$E_{r}^{i}<40$ & low & $\mathrm{RI}<150$ & low risk(LR) \\
\hline $40 \leq E_{r}^{i}<80$ & medium & $\begin{array}{c}150 \leq \mathrm{RI}< \\
300\end{array}$ & $\begin{array}{l}\text { medium } \\
\text { risk(MR) }\end{array}$ \\
\hline $80 \leq E_{r}^{i}<160$ & $\begin{array}{l}\text { equivalent } \\
\text { high }\end{array}$ & $\begin{array}{c}300 \leq \mathrm{RI}< \\
600\end{array}$ & high $\operatorname{risk}(\mathrm{HR})$ \\
\hline $160 \leq E_{r}^{i}<320$ & high & $\mathrm{RI} \geq 600$ & \\
\hline
\end{tabular}
soil in Henan Province refer to reference[11]).

Table 1. Potential ecological risk level[10] very high

risk(VHR)

\subsection{Improved potential ecological risk index (IER)}

It is widely recognized that the distribution, mobility, bio-availability and eco-toxicity of heavy metals in the environment depend not only on their total concentration but also on their chemical speciation. Chen[12] established the relationship among fractions of heavy metals, eco-toxicity, and bio-availability through the European Community Bureau of Reference(BCR) sequential extraction. It is be verified that 1)acid soluble/exchangeable fraction(F1) and reducible fraction(F2) are direct toxicity, 2) oxidizable fraction(F3) is potential toxicity,3)residual fraction(F4) is no toxicity.

Considering the influence of chemical forms on the toxicity of heavy metals, a potential ecological risk analysis method based on fractions was established in this study, which is as follow.

$$
\begin{gathered}
C_{f}^{i},=C_{D}^{i}(F 1+F 2) \times 1.2+C_{D}^{i}(F 3) \times 0.6+C_{D}^{i}(F 4) \times 0 \\
C_{f}^{i,}=C_{D}^{i} / C_{R}^{i} \\
E_{r}^{i},=T_{r}^{i} \times C_{f}^{i}, \\
R I=\sum_{i=1}^{n} E_{r}^{i,}=\sum_{i=1}^{n} T_{r}^{i} \times C_{f}^{i},
\end{gathered}
$$

\section{Results and discussion}

\subsection{Total concentration of the heavy metals}

According to the experimental analysis results, the concentrations of the heavy metals in road dust at 15 sampling points of the Third Ring Road in Zhengzhou in 2018 are shown in Table 2.

The results showed that the concentrations of As, $\mathrm{Zn}$, $\mathrm{Cd}$ and $\mathrm{Cu}$ in all sampling sites exceeded the soil background values. The concentrations of $\mathrm{Mn}$ were lower than the background value. $\mathrm{Pb}$ and $\mathrm{Cr}$ exceeded the background value at partial sampling sites. Except $\mathrm{Mn}$ and $\mathrm{Cr}$, the average value of the other five heavy metals exceeded the background value. The pollution of As and $\mathrm{Cd}$ were relatively serious. The concentrations of heavy metals in sampling sites 10\#, 12\#, 13\# and 14\# were relatively high, mainly due to long-term road construction of 10\#, 12\#, 13\#. 14\# are located at the overpass of North Third Ring Road of Zhongzhou Avenue, which belong to the main traffic road. Thus, the more motor vehicles and more pollutants such as exhaust gas, results in relatively serious total metal pollution at sampling site $14 \#$. 
Table 2. Total concentrations of the heavy metals $\quad(\mathrm{mg} / \mathrm{kg})$

\begin{tabular}{cccccccc}
\hline $\begin{array}{c}\text { Samplin } \\
\text { g site }\end{array}$ & As & Zn & Pb & Cd & Mn & Cr & Cu \\
\hline 1 & 17.00 & 268.07 & 18.07 & 2.50 & 86.10 & 27.90 & 29.50 \\
2 & 18.40 & 122.20 & 17.27 & 2.50 & 104.93 & 48.50 & 22.63 \\
3 & 19.57 & 213.30 & 19.03 & 3.13 & 91.03 & 40.40 & 35.70 \\
4 & 19.77 & 166.17 & 62.70 & 1.67 & 72.13 & 42.43 & 35.00 \\
5 & 20.23 & 157.00 & 21.43 & 2.50 & 82.53 & 29.07 & 30.27 \\
6 & 21.37 & 101.27 & 17.90 & 2.50 & 90.87 & 33.27 & 42.93 \\
7 & 24.37 & 280.23 & 19.40 & 2.50 & 76.57 & 20.77 & 24.17 \\
8 & 23.87 & 155.17 & 16.63 & 2.50 & 84.83 & 26.47 & 29.27 \\
9 & 24.50 & 253.83 & 20.50 & 2.50 & 102.97 & 42.53 & 42.53 \\
10 & 25.95 & 214.65 & 21.17 & 3.98 & 154.40 & 61.65 & 43.78 \\
11 & 22.40 & 115.90 & 14.90 & 2.50 & 117.83 & 16.97 & 20.10 \\
12 & 25.70 & 218.30 & 94.70 & 2.70 & 184.10 & 59.20 & 56.87 \\
13 & 24.67 & 233.83 & 20.97 & 2.50 & 190.33 & 93.87 & 61.17 \\
14 & 24.73 & 159.33 & 21.13 & 3.03 & 183.13 & 81.43 & 79.50 \\
15 & 24.80 & 183.90 & 19.87 & 2.90 & 137.97 & 54.50 & 43.67 \\
Min & 17.00 & 101.27 & 14.90 & 1.67 & 72.13 & 20.77 & 20.10 \\
Max & 25.95 & 280.23 & 94.70 & 3.98 & 190.33 & 93.87 & 79.50 \\
AVE & 22.49 & 192.21 & 27.04 & 2.66 & 117.32 & 45.26 & 39.81 \\
SD & 2.88 & 53.18 & 21.91 & 0.49 & 41.93 & 21.93 & 16.14 \\
und & 9.8 & 62.5 & 21.8 & 0.064 & 560 & 63.3 & 20 \\
\hline alue[14] & & & & & & & \\
\hline
\end{tabular}

The fractions of the heavy metals was analyzed through the European Community Bureau of Reference (BCR) sequential extraction.

\subsection{Traditional Potential risk assessment}

The traditional potential risk index of single heavy $\operatorname{metal}\left(E_{r}^{i}\right)$ and the total risk (RI) were shown in Table 3.

Table 3. The traditional potential risk index of heavy metals

\begin{tabular}{|c|c|c|c|c|c|c|c|c|}
\hline \multirow{2}{*}{$\begin{array}{l}\text { Samplin } \\
\text { g site }\end{array}$} & \multicolumn{6}{|c|}{$E_{r}^{i}$} & \multirow{2}{*}{ RI } & \multirow{2}{*}{$\begin{array}{l}\text { Risk } \\
\text { level }\end{array}$} \\
\hline & As & $\mathbf{Z n}$ & $\mathbf{P b}$ & Cd & $\mathrm{Cr}$ & $\mathrm{Cu}$ & & \\
\hline $1 \#$ & 17.35 & 4.29 & 4.14 & 1171.88 & 0.88 & 7.38 & 1205.91 & VHR \\
\hline $2 \#$ & 18.78 & 1.96 & 3.96 & 1171.88 & 1.53 & 5.66 & 1203.76 & VHR \\
\hline $3 \#$ & 19.97 & 3.41 & 4.37 & 1468.75 & 1.28 & 8.93 & 1506.70 & VHR \\
\hline $4 \#$ & 20.17 & 2.66 & 14.38 & 781.25 & 1.34 & 8.75 & 828.55 & VHR \\
\hline $5 \#$ & 20.65 & 2.51 & 4.92 & 1171.88 & 0.92 & 7.57 & 1208.43 & VHR \\
\hline $6 \#$ & 21.80 & 1.62 & 4.11 & 1171.88 & 1.051 & 10.73 & 1211.19 & VHR \\
\hline $7 \#$ & 24.86 & 4.48 & 4.45 & 1171.88 & 0.66 & 6.04 & 1212.37 & VHR \\
\hline $8 \#$ & 24.35 & 2.48 & 3.81 & 1171.88 & 0.84 & 7.32 & 1210.68 & VHR \\
\hline 9\# & 25.00 & 4.06 & 4.70 & 1171.88 & 1.341 & 10.63 & 1217.62 & VHR \\
\hline $10 \#$ & 26.48 & 3.43 & 4.85 & 1867.19 & 1.951 & 10.95 & 1914.85 & VHR \\
\hline $11 \#$ & 22.86 & 2.49 & 3.42 & 1171.88 & 0.54 & 5.03 & 1206.21 & VHR \\
\hline $12 \#$ & 26.22 & 3.49 & 21.72 & 1265.63 & 1.871 & 14.22 & 1333.15 & VHR \\
\hline
\end{tabular}

$\begin{array}{llllllllll}13 \# & 25.17 & 3.74 & 4.81 & 1171.88 & 2.97 & 15.29 & 1223.85 & \text { VHR }\end{array}$

$\begin{array}{lllllllllll}14 \# & 25.24 & 2.55 & 4.85 & 1421.88 & 2.57 & 19.88 & 1476.96 & \text { VHR }\end{array}$

$\begin{array}{llllllllllll}15 \# & 25.31 & 2.94 & 4.56 & 1359.38 & 1.72 & 10.92 & 1404.82 & \text { VHR }\end{array}$ $\begin{array}{llllllll}\text { Average } & 22.95 & 3.08 & 6.20 & 1247.40 & 1.43 & 9.95 & 1291.00\end{array}$

It can be seen from Table 3 that the risk of single heavy metal except $\mathrm{Cd}$ is less than 40 , which means that the potential ecological risk is low risk. The order of potential risk of single metal was $\mathrm{Cd}>\mathrm{As}>\mathrm{Cu}>\mathrm{Pb}>$ $\mathrm{Zn}>\mathrm{Cr}$.

Among the 15 sampling sites, the total risk of $10 \#$ is the highest, which is 1914.85 . The total risk of 4 \#is the lowest, with the value of 828.55. However, the total risks of the 15 sampling sites were all belong to very high risk level, which need to be paid special attention by the management department. The main reason is that the risk value of $\mathrm{Cd}$ is too high, with the minimum risk of 781.25 and the average value of 1247.40. Therefore, Cd should be the primary control pollutant.

\subsection{Improved potential ecological risk index}

The risks of single heavy metal and the total risks (IRI) analyzed by potential ecological risk index based on heavy metals chemical speciation were shown in Table 4.

Table 4. The improved potential risk index of heavy metals

\begin{tabular}{|c|c|c|c|c|c|c|c|c|}
\hline \multirow{2}{*}{$\begin{array}{c}\text { Samplin } \\
\text { g site }\end{array}$} & \multicolumn{6}{|c|}{$E_{r}^{i}$} & \multirow{2}{*}{ IRI } & \multirow{2}{*}{$\begin{array}{l}\text { Risk } \\
\text { level }\end{array}$} \\
\hline & As & $\mathrm{Zn}$ & $\mathbf{P b}$ & Cd & $\mathrm{Cr}$ & $\mathbf{C u}$ & & \\
\hline $1 \#$ & 11.31 & 0.19 & 1.96 & 0.00 & 0.06 & 1.57 & 15.10 & LR \\
\hline $2 \#$ & 13.33 & 0.17 & 2.13 & 0.00 & 0.06 & 1.68 & 17.36 & LR \\
\hline $3 \#$ & 12.27 & 0.22 & 2.00 & 279.69 & 0.08 & 3.27 & 297.52 & MR \\
\hline $4 \#$ & 13.39 & 0.25 & 5.18 & 0.00 & 0.18 & 1.78 & 20.77 & LR \\
\hline $5 \#$ & 14.84 & 0.20 & 1.74 & 0.00 & 0.05 & 1.26 & 18.09 & LR \\
\hline $6 \#$ & 15.94 & 0.25 & 1.88 & 0.00 & 0.06 & 4.00 & 22.12 & LR \\
\hline $7 \#$ & 18.16 & 0.46 & 2.18 & 0.00 & 0.06 & 1.22 & 22.08 & LR \\
\hline $8 \#$ & 16.51 & 0.67 & 1.87 & 0.00 & 0.05 & 2.23 & 21.33 & LR \\
\hline 9\# & 17.73 & 0.89 & 2.64 & 0.00 & 0.07 & 5.00 & 26.33 & LR \\
\hline $10 \#$ & 18.27 & 0.65 & 2.51 & 54.69 & 0.06 & 4.52 & 80.70 & LR \\
\hline $11 \#$ & 17.63 & 0.59 & 2.05 & 0.00 & 0.06 & 2.54 & 22.87 & LR \\
\hline $12 \#$ & 19.20 & 1.27 & 3.22 & 112.50 & 0.18 & 9.92 & 146.29 & LR \\
\hline $13 \#$ & 19.24 & 0.97 & 2.34 & 0.00 & 0.17 & 9.84 & 32.56 & LR \\
\hline $14 \#$ & 19.33 & 1.07 & 2.73 & 300.00 & 0.19 & 14.18 & 337.49 & HR \\
\hline $15 \#$ & 19.41 & 0.70 & 2.12 & 225.00 & 0.12 & 5.58 & 252.93 & MR \\
\hline Average & 16.44 & 0.57 & 2.44 & 64.79 & 0.10 & 4.57 & 88.90 & I \\
\hline
\end{tabular}

It can be seen from Table 4 that compared with the results of potential ecological risk assessment (Table 3), the biological toxicity of different chemical forms of heavy metals was considered in the improved potential ecological risk index. According to the reference[12], the residue is non-toxic. The results of the improved potential ecological risk assessment showed that the total risks of $3 \#$ and 15\# were MR. The highest risk appeared on14 \# with the value of 337.49 , which 
belonged to HR, and the total risk of the other sampling sites were LR.

The evaluation results of the two assessment methods are quite different, which mainly depends on the toxicity of different chemical forms of heavy metals. Since residual fraction( $\mathrm{F} 4)$ of $\mathrm{Cd}$ are non-toxic in the samples, the results of the improved potential ecological risk index were much lower than the traditional potential ecological risk index. In the evaluation process, it is more scientific to consider the ecological toxicity of the heavy metal fractions, which is more in line with the real situation than using the total concentration, so as to avoid the wrong management decision.

\section{Conclusion}

In all sampling sites, the concentrations of $\mathrm{As}, \mathrm{Zn}, \mathrm{Cd}$ and $\mathrm{Cu}$ exceeded the soil background values. The concentration of $\mathrm{Mn}$ was lower than the background value. $\mathrm{Pb}$ and $\mathrm{Cr}$ exceeded the background value at partial sampling sites. Except $\mathrm{Mn}$ and $\mathrm{Cr}$, the average value of the other five heavy metals exceeded the background value. The pollution of $\mathrm{As}$ and $\mathrm{Cd}$ were relatively serious.

According to the traditional potential ecological risk index, the order of potential risk of single risk was $\mathrm{Cd}>$ $\mathrm{As}>\mathrm{Cu}>\mathrm{Pb}>\mathrm{Zn}>\mathrm{Cr}$. Among the 15 sampling sites, the total risk of 10 \#is the highest, which is 1914.85. The total risk of 4 \#is the lowest, which is 828.55 . However, the total risks of the 15 sampling sites were all belong to very high risk level, which need to be paid special attention by the management department. The main reason is that the risk value of $\mathrm{Cd}$ is too high, with the minimum risk of 781.25 and the average value of 1247.40. Therefore, Cd should be the primary control pollutant.

According to the improved potential ecological risk index, the total risks of $3 \#$ and $15 \#$ were MR. The highest risk appeared on14\# with the value 337.49, which belonged to HR, and the total risk of the other sampling sites were LR. Therefore, 14\# should be the primary control site. Since residual fraction(F4) of $\mathrm{Cd}$ are nontoxic in the improved method, the results of the improved potential ecological risk index were much lower than the traditional potential ecological risk index.

It can be seen that there is a big difference in the risk of Cd between the two methods. The risk is very high in the traditional evaluation method, but low in the improved method. In the evaluation process, it is more scientific to consider the ecological toxicity of heavy metal fractions, which is more in line with the real situation than using the total concentration, so as to avoid the wrong management decision.

\section{Acknowledgement}

This study was funded by the National Natural Science Foundation of China (Grant Nos. U1704123 and U1704126), and the Scientific Research Foundation project of Henan University of Technology ( No. 2016QNJH07).

\section{References}

1. P. G. Satsangi, S. Yadav, A. S. Pipal, N.Kumbhar. Characteristics of trace metals in fine (PM2.5) and inhalable (PM10) particles and its health risk assessment along with in-silico approach in indoor environment of India. Atmospheric Environment.(2014) 92:384-393.

2. Z.G. Li, X.B. Feng, G.H. Li, X.Y. Bi, J.M. Zhu, H.B. Qin,Z.H. Dai, J.L. Liu, Q.H. Li, G.Y. Sun. Distributions, sources and pollution status of 17 trace metal/metalloids in the street dust of a heavily industrialized city of central China. Environmental Pollution. (2013) 182 408-416.

3. C. Men, R.M. Liu, F. Xu,Q.R. Wang, L.J. Guo, Z.Y. Shen.Pollution characteristics, risk assessment, and source apportionment of heavy metals in road dust in Beijing, China.Science of the Total Environment, (2018)612:138-147.

4. I.C. Yadav, N.L. Devi, V.K. Singh, J. Li, G. Zhang. Spatial distribution, source analysis, and health risk assessment of heavy metals contamination in house dust and surface soil from four major cities of Nepal.Chemosphere (2019) 218:1100-1113.

5. M. Zhang, X.P. Li, R. Yang,J.W. Wang, Y.W. Ai, Y. Gao, Y.C. Zhang, X. Zhang, X.Y. Yan, B. Liu, H.T. Yu. Multipotential Toxic Metals Accumulated in Urban Soil and Street Dust from Xining City, NW China: Spatial Occurrences, Sources, and Health Risks.Archives of Environmental Contamination and Toxicology (2019)76:308-330.

6. A. Mihailović, L. Budinski-Petković,S. Popov, J. Ninkov, J. Vasin, N.M. Ralević, M. Vučinić Vasić. Spatial distribution of metals in urban soil of Novi Sad, Serbia: GIS based approach. J Geochem Explor (2015)150:104-114.

7. X. Wei, B. Gao, P.Wang, H. Zhou, J. Lu Pollution characteristics and health risk assessment of heavy metals in street dusts from different functional areas in Beijing, China. Ecotoxicol Environ Saf (2015) 112:186-192.

8. J. Wang, Z. Chen, X. Sun, G. Shi, S. Xu, D. Wang, L. Wang. Quantitative spatial characteristics and environmental risk of toxic heavy metals in urban dusts of Shanghai, China. Environ. Earth Sci. (2009)59: 645-654.

9. J. Zhang, P. Hua, P. Krebs. The build-up dynamic and chemical fractionation of $\mathrm{Cu}, \mathrm{Zn}$ and $\mathrm{Cd}$ in road-deposited sediment. Sci. Total Environ. (2015)532: 723-732.

10. L. Hakanson. An ecological risk index for aquatic pollution control, a sedimentological approach. Water Research.(1980) 14: 975-1001.

11. F.S. Shao, H.Y. Zhou.Soil environmental background values of main elements in Henan Province.Henan agriculture.(1998)10:29.

12. M. Chen, X.M. Li, Q. Yang, G.M. Zeng, Y. Zhang, D.X. Liao, J.J. Liu, J.M. Hu, L. Guo. Total concentrations and speciation of heavy metals in municipal sludgefrom Changsha, Zhuzhou and Xiangtan in middle-south region of China. J.Hazard. Mater. (2008)160:324 - 329. 